\title{
The Research Progress of Mesenchymal Stem Cells in the Treatment of Traumatic Brain Injury
}

\author{
Gang LI ${ }^{1^{*}}$, Yue YANG ${ }^{1 *}$, Hua-jiang DONG ${ }^{1,2}$, Ling LIN ${ }^{1}$ \\ ${ }^{1}$ Tianjin University, State Key Laboratory of Precision Measurement Technology and Instruments, Tianjin, China \\ ${ }^{2}$ Logistics University of Chinese People's Armed Police Forces, Tianjin, China \\ *Gang LI and Yue YANG were contributed equally to this work.
}

\section{ABSTRACT}

Traumatic brain injury (TBI) is the leading cause of mortality and morbidity in children and adults throughout the world. It is urgent to ameliorate TBI damage and reduce the disability and case-fatality rate. Stem cell therapy is another medical revolution after drug and surgical medication. Mesenchymal stem cells (MSCs) are a class of cells with significant self-renewal and multi-lineage differentiation properties. They are favorable for the treatment of various diseases and injuries. It could be envisioned that MSCs transplantation may be a promising treatment for TBI. Currently, stem cell therapy has shown promising effects in the treatment of many diseases. In this article, we will review the characteristics of MSCs, MSCs for neuronal function restoration, the properties of immune-modulatory of MSCs, and the anti-apoptotic effects of MSCs, the angiogenesis effect of MSCs, and the safety issues in MSCs therapy in TBI.

KEYWORDS: Angiogenesis, Anti-apoptosis, Immunomodulatory, Mesenchymal stem cell, Umbilical cord, Traumatic brain injury

\section{INTRODUCTION}

$\mathrm{T}$

Traumatic brain injury (TBI) results from external forces, the consequence of direct impact, rapid acceleration or deceleration, a penetrating object, or blast waves from an explosion (38). According to the pathology, TBI involves primary injury and secondary injury. Primary injury occurs at the initial phase of trauma; the rapid deformation of brain tissue gave rise to focal contusion, haematomas, vascular damage and axonal injury, evolved membranolysis, cellular content efflux, hemodynamics disturbance and neuronal necrosis (41). Secondary injury comes after the primary injury, and causes a complex series of cellular and biochemical processes (51). Electronic, including blood brain barrier (BBB) disruption, excitatory amino acid (EAA) release, free-radical generation, calcium-mediated damage, gene activation, mitochondrial dysfunction, and inflammatory responses, and elicits an arrangement disorder, apoptosis and even loss of nerve cells (53).
The pathomechanism of $\mathrm{TBI}$ is unequivocal, but there are no effective strategies to reduce the loss of neurons, inhibiting apoptosis and increasing neurogenesis. TBI not only tortures numerous patients by permanent disability and cognitive dysfunction $(5,33)$, it also imposes a heavy economic burden on their families and society $(2,76)$. With rapid development of stem cells, many scientists and medical researchers are pinning their hopes on stem cell technology, and stem cells may be a prominent medication for TBI.

\section{MATERIAL and METHODS}

A PubMed search was performed, using the phrase "Mesenchymal stem cells and Traumatic brain injury," for all years up to 2017. The references of systematic reviews were examined for additional sources. These articles were reviewed based on immunomodulatory properties, angiogenesis, anti-apoptosis, neuronal function restoration of the injured nervous system, and security analysis. Eighty-five articles were chosen for this review. 


\section{- REVIEW}

Mesenchymal stem cells (MSCs) are a class of cells with significant self-renewal and multi-lineage differentiation properties, and can be harvested from bone marrow, adipose tissue, skin, umbilical cord blood, umbilical cord and peripheral blood as well as other organs. MSCs can be defined by the expression of surface molecular epitopes (CD73, CD90, CD105), and the lack of several surface markers (CD34, CD45, CD19, CD11b). MSCs express intermediate levels of human leukocyte antigen (HLA) major histocompatibility complex class I (MHC-I) molecules and negligibly low levels of HLA class II (HLA-II) and Fas ligand (30); they do not express the co-stimulatory molecules B7-1, B7-2, CD40, or CD40L. Promisingly, the hypoallergenic state of MSCs makes them difficult to be recognized by HLA incompatible receptors. Preclinical studies have shown that MSCs derived from bone marrow have therapeutic potential for treating a number of acute limb ischemia disease (75), myocardial ischemia $(63,82)$, myocardial infarction (11), and cerebral hemorrhage. Furthermore, MSCs have also been reported to alleviate neurodegenerative diseases $(22,26,54)$. A new class of cells with self-renewal and multi-lineage differentiation properties collected from neonatal umbilical cord tissue was named as umbilical cord derived mesenchymal stem cell (UCMSC) $(10,34,77)$ andcould be incubated to differentiate into neuron-like cells, and express nestin, neuron-specific enolase (NSE), neurofilament (NF), glial fibrillary acidic protein (GFAP). Umbilical cord mesenchymal stem cellx (UCMSC) may be an ideal source due to the accessibility, painless procedures to donors, promising sources for cell therapy and lower risk of viral contamination.

To date, there are no efficient strategies aimed to alleviate neuron loss and promote nerve regeneration. Stem cells may have this potential. Some studies have shown that this might be due to the migration and homing (23), and differentiation into neuronal cells $(14,52,61)$. However, increasing research suggests that the therapeutic results of MSCs might be due to the trophic factors and anti-apoptosis proteins to modulate host micro-environment (42), rather than replacing the damaged cell (58), and according to studies, the therapeutic effects of MSCs on TBI is mainly reflected in restoring neural function, reducing apoptosis, regulating immune response or immunosuppressive effects, and promoting angiogenesis (21), while preclinical research suggests that it is remarkable for MSCs transplanted in neurodegenerative disorder and spinal cord injury including TBI and cerebral infraction $(25,70)$.

MSCs could be differentiated into neurons and glial cells and could ameliorate extracellular microenvironment, promote axonal regeneration and suppress cell apoptosis by expressing neurotrophic factors in vivo. And MSCs could make up the lesion area so as to inhibit the excessive proliferation of glial cells. Kopen et al. found MSCs can migrate throughout the forebrain and cerebellum without disruption to the brain architecture (27). Some MSCs in the striatum and the molecular layer of the hippocampus expressed GFAP, and therefore, differentiated into mature astrocytes. In addition, neurofilament positive donor cells were found in the reticular formation of the brain stem, suggesting that MSCs also may have differenti- ated into neurons. Brazelton et al. injected GFP-expressing bone marrow-derived cells into mouse by tail vein, the results revealed that hundreds of marrow-derived cells in brain sections expressed neurons makers (NeuN, 200-kilodalton neurofilament, and class III $\beta$-tubulin) (9). Similarly, Mezey et al. found transplanted bone marrow MSCs could migrate into the brain and differentiated into cells that expressed NSE (44). Zhao et al. found that the Wnt3a protein secreted by MSCs recapitulates part of the neuroprotective and neurogenic effects (84), they can promote the restoration of neurocognitive function. These results indicate that the potential therapeutic mechanism, at least in part to the release of soluble factors after intravenous MSC administration.

Some kinds of crucial endogenous protective factors were founded, including neurotrophic factors, gangliosides (57), heat shock proteins (HSP), adenosine, magnesium et al. They could moderate the secondary neuronal injury, promote axonal regeneration and repair the damaged neurons in vivo and in vitro. However, most of neurotrophic factors cannot pass through the blood brain barrier, but MSCs could reduce blood brain barrier permeability, increase neuronal survival, and improve neurocognition $(43,62,66)$.

MSCs express intermediate levels of human leukocyte antigen (HLA) major histocompatibility complex (MHC) class I molecules and negligibly low levels of HLA class II and Fas ligand, they do not express the co-stimulatory molecules B7-1, B7-2, CD40, or CD40L. Consequently, MSCs present low immunogenicity and immune regulatory properties or immunosuppressive properties. They can escape recognition by heterogeneous T lymphocyte. MSCs up-regulated MHCII expression affected by interferon- $\gamma$ (INF- $\gamma)$, whereas the inhibition of MSCs was not dependent on MHC, which contribute to the low immunogenicity of MSCs (39), and lay the foundation for MSCs cell therapy in clinical application. Tse et al. confirmed that MSCs could not stimulate allogeneic T cells or peripheral blood mononuclear cells in mixed culture system, which indicated that USMSCs may not express MHC-land and MHC-II (65). Weiss et al. transplanted porcine umbilical cord MSCs into rats' brain without immunosuppressant, the result showed that MSCs migrated into rats' brain and expressed porcine nerve cells marker, reflected that MSCs can escape from host immune system attacking (72).

TBI induces a strong inflammatory response characterized by recruitment of peripheral leukocytes into the brain parenchyma and activation of endogenous immune cells $(55,85)$. Neutrophil, monocytes and lymphocytes around the brain directly affect the survival and death of neural cells $(20,35,55,85)$. In addition, activated microglial cells migrate to the injured tissue, and releasing the cytokines, chemokines, active oxygen, nitric oxide, proteases and other cytotoxicity substances may aggravate neuronal death $(15,35)$. However, immune cells and inflammatory mediators may also play neuroprotective roles in TBI (46). For example, T lymphocytes may play a role in promoting repair in late brain injury $(4,8)$. Proinflammatory cytokines interleukin-1 (IL-1), interleukin-6 (IL-6) and tumor necrosis factor-a (TNF-a) have both beneficial and detrimental effects on nerve cells $(20,66,74)$. Microglia also can clear necrotic debris in brain tissue, promote the 
re-modeling of brain cells, and exert neuroprotective effects in some specific conditions $(3,7,85)$. It is indicated that the inflammatory reaction caused by $\mathrm{TBI}$ is a crucial factor in secondary brain injury, and it may be effective and protective for a series of pathological process by anti-inflammatory or immune regulatory treatment. MSCs can affect immune cells proliferation, differentiation, activation and inflammatory cytokine secretion by cells interaction and secretion of soluble immune regulatory factors and inhibit the proliferation of $T$ cells and microglia, regulate dendritic cells, monocytes and macrophages and natural killer (NK) cells secrete cytokines $(16,42,47,49)$. Moreover, MSCs harvested from umbilical cord, pancreas, skeletal muscle and placenta present the same effects as bone marrow derived. But the exact mechanism in inflammation and immunosuppression is not clear. MSCs could induce peripheral immune tolerance and migrate to the damaged tissue, could inhibit pro-inflammatory cytokines release and promote the damaged cells survival (67), and MSCs achieved remarkable therapeutic effects in the treatment of acute lung injury $(13,45)$, myocardial infarction (1), acute renal failure (56), cerebral ischemia (59), and Alzheimer's disease (31). It found that MSCs have inflammatory regulatory functions. One of the studies confirmed that UCMSCs have anti-inflammatory effects in the rat stroke model (68). Another study reported that neural stem cells of intravenous injected in the acute phase of stroke can interact with the peripheral inflammatory system to regulate and ameliorate congenital encephalitis (32). These studies demonstrate the feasibility of using MSCs transplantation to reduce cerebral tissue inflammation and regulate immune responses (83). TBI induced brain inflammatory response and MSCs play a role of regulating inflammatory, which is indicating the possibility of reducing the inflammatory response.

Apoptosis could be trigged by many intrinsic and extrinsic signals. The possible mechanisms of traumatic brain cell apoptosis involved in the increase of free radicals, the activation of the transcription signal and the gene expression (36). At present, varieties of related genes or factors have been found, such as bcl-2, c-my c, p53, ICE and fas. Recent studies have found that, the expression of bcl-2 and bcl-x protein in the CA3 area of stroke side hippocampus decreased significantly 6 hours after injury, while the expression of bax did not change significantly. Bcl-2 gene family participated in the apoptosis of neuronal cells after brain injury. The expression of different members of the gene family was involved in the apoptosis of neural cells (37). As reported, MSCs present anti-apoptotic effect. MSCs could up-regulate the expression of anti-apoptotic protein bcl-2 and promote angiogenesis of infarcted region by activating the PI3K/Akt signal pathway.

In the acute phase of cerebral ischemia reperfusion injury, MSCs could reduce apoptosis and significantly improve neural function after cerebral ischemia by promoting survivin apoptosis protein and suppressing Caspase-3 apoptosis protein expression in rats. In renal ischemia reperfusion injury model, MSCs could also inhibit the apoptosis of renal tubular epithelial cells by down-regulate the expression of bax of bcl2 family $(28,64,79)$. Recently our studies further confirmed the effects of regulating apoptosis.
After TBI, the degeneration and necrosis of nerve cells caused by ischemia and hypoxia lead to neurological deficits. Marshall found that $90 \%$ of patients died in TBI had ischemic changes, and ischemia was the main mechanism of secondary damage (40). Neovascularization in the peripheral tissue of brain injury is the major prerequisite for improving blood circulation and the basis of synaptic communication and functional reconstruction (50). Accordingly, it is very important to restore the blood supply of ischemic region as soon as possible. Angiogenesis processes consist of angiogenesis, vasculogenesis and mature capillary networks formed by the original vascular shear remodeling. Numerous of cytokines were released after cerebral ischemia; they could, but limitedly, trigger angiogenesis so as to reduce the damage caused by cerebral ischemia. Angiogenesis treated by MSCs transplantation has got a research focus throughout the world. MSCs showed highly proliferate, differentiate, plasticity, rapidly amplify properties, and chemotaxis to injured tissue. They could differentiate into endothelial cells, vascular smooth muscle cell, and Schwann cells with hypoxic conditions, furthermore, and MSCs could secrete cytokines through autocrine and paracrine mechanism, including vascular endothelial growth factor, stromal cell derived factor-1, monocyte chemo-attractant protein, neurotrophic factor, etc., which contribute to promote angiogenesis $(6,69)$.

The exact mechanisms of MSCs promote angiogenesis is not clear yet, most studies suggest that the differentiation of MSCs has an intimate relativity with its microenvironment. After ischemia or injury, it may be the variety of factors in the microenvironment of lesion tissue promotes MSCs differentiate into cells or tissues which the environment needed (17). As speculation, it may work by the following mechanisms: MSCs are integrated into the damaged vessels after transplantation to participate in the formation of ischemic tissue and provide endothelial cells for neovascularization $(60,73)$. On the other hand, MSCs secret a variety of cytokines and growth factors through paracrine, including vascular endothelial growth factor (VEGF), basic fibroblast growth factor (BFGF), hepatocyte growth factor, hypoxia-inducible factor-1a (HIF-1a), interleukin-8 (IL-8), interleukin-6 (IL-6) and TNF-a, to induce microvascular generation, stimulate peripheral mature endothelial cells proliferation and migration, improve the microenvironment of ischemic tissue to participate in angiogenesis $(12,24,29,71)$. Zhang et al. demonstrated that exosomes from human umbilical cord mesenchymal stem cells (UC-MSC-Ex) could promote cutaneous wound healings (81). Further, they proved UC-MSC-Ex could promote endothelial cells proliferation, migration and tube formation in-vivo and in-vitro (81). They found that UC-MSC-Ex could also repair a severe second-degree skin injury through delivering Wnt and activating Wnt/b-catenin signal pathway to promote angiogenesis (81). Studies have shown that angiogenesis plays an important role in initiating and promoting nerve regeneration after injury. It would be helpful, if restoring the structure and function of endothelial cells and promote the formation of new blood vessels in brain injury ischemia as soon as possible, to improve brain tissue metabolism, promote penumbra damaged neurons repair (19), induce neurogenesis, acceler- 
ate toxic products clearance, deliver oxygen and nutrients to provide a livable microenvironment for the survival, migration and differentiation of implanted cells (80).

The clinical safety of MSCs has been concerned by both doctors and patients. If the MSCs for therapy were used unsafely or improperly, they might result in some side effects, even get a tumor or cancer. Irregular MSCs therapy contains potential danger. It is necessary to evaluate the systematic safety before treatment. There have been tremendous researches about MSCs, we suggest that numerous preliminary clinical trial on cell biological research and standardization of MSCs are indispensable, especially the clinical safety research. Meanwhile, government should formulate a series of regulations and standards to regulate stem cell therapy.

\section{DISCUSSION}

Accumulating evidences reported that MSCs transplantation have achieved remarkable effects for the treatment of cerebral infarction, cerebral hemorrhage, neuronal degeneration disease and spinal cord injury $(26,48)$. The therapeutic effects of MSCs on central nervous system injury seem to have been confirmed, but its therapeutic mechanism for brain injury is not yet clear. The original intent of stem cell transplantation in the treatment of central nervous system injury is cell replacement therapy, namely stem cells can differentiate into mature neurons and glial cells to replace damaged neural cells owing to the ability of proliferation and differentiation. Experiment showed the neurological function of MSCs treatment group was significantly improved one week after MSCs transplantation (78). In such a short time, MSCs apparently cannot differentiate into mature functional neurons, even cannot integrate into the host structure and participate in complex neural networks. Furthermore, Hasan et al. suggest that only a small percentage of intravenously injected MSCs reached brain after being filtered by the lung tissue (18). We suggest that MSCs repair damaged tissue by 'bystander effect'. The transplanted stem cells secrete trophic factors, anti-inflammatory factors and other bioactive molecules that interact with injured and/or normal body.

\section{CONCLUSION}

We suggest MSCs repair damaged tissue in TBI contains the 'bystander effect'. MSCs could be guided by the chemotaxis, inflammatory substance and could migrate to the lesion area, and preferentially release the nutritional factors and play the role of anti-apoptosis. Stem cell therapy is another medical revolution after drug and surgical medication. The research of MSCs developed rapidly from basic research to clinical application; scientists in the field of stem cells should seize the technical commanding point with the continuous development of science and technology in stem cell.

\section{ACKNOWLEDGEMENT}

Our study received support from the Natural Science Foundation of China (81401295), the natural Science Fund project in Tianjin (NO. 16JCYBJC27600).

\section{- REFERENCES}

1. Agrba VZ, Porkhanov VA, Karal-Ogly DD, Leontyuk AV, Kovalenko AL, Sholin IY, Gvozdik TE, Ignatova IE, Agumava AA, Chuguev YP, Gvaramiya IA, Lapin BA: Transplantation of simian mesenchymal stem cells to baboons with experimentally induced myocardial infarction. Bull Exp Biol Med 160: 589-591, 2016

2. Ahmed Al, Shtaya AB, Zaben MJ, Owens EV, Kiecker C, Gray WP: Endogenous GFAP-positive neural stem/progenitor cells in the postnatal mouse cortex are activated following traumatic brain injury. J Neurotrauma 29: 828-842, 2012

3. Aloisi F: Immune function of microglia. Glia 36:165-179, 2001

4. Arneth BM: Protective autoimmunity and protein localization. J Neuroimmunol 219: 123-125, 2010

5. Beauchamp K, Mutlak H, Smith WR, Shohami E, Stahel PF: Pharmacology of traumatic brain injury: Where is the "golden bullet"? Mol Med 14:731-740, 2008

6. Bernardi S, Severini GM, Zauli G, Secchiero P: Cell-based therapies for diabetic complications. Exp Diabetes Res 2012: 872504, 2012

7. Biber K, Neumann H, Inoue K, Boddeke HW: Neuronal 'On' and 'Off' signals control microglia. Trends Neurosci 30:596602,2007

8. Brait VH, Arumugam TV, Drummond GR, Sobey CG: Importance of T lymphocytes in brain injury, immunodeficiency, and recovery after cerebral ischemia. J Cereb Blood Flow Metab 32: 598-611, 2012

9. Brazelton TR, Rossi FM, Keshet GI, Blau HM: From marrow to brain: Expression of neuronal phenotypes in adult mice. Science 290: 1775-1779, 2000

10. Cai J, Li W, Su H, Qin D, Yang J, Zhu F, Xu J, He W, Guo X, Labuda K, Peterbauer A, Wolbank S, Zhong M, Li Z, Wu W, So KF, Redl H, Zeng L, Esteban MA, Pei D: Generation of human induced pluripotent stem cells from umbilical cord matrix and amniotic membrane mesenchymal cells. J Biol Chem 285: 11227-11234, 2010

11. Cai M, Shen R, Song L, Lu M, Wang J, Zhao S, Tang Y, Meng $X$, Li Z, He ZX: Bone marrow mesenchymal stem cells (BMMSCs) improve heart function in swine myocardial infarction model through paracrine effects. Sci Rep 6: 28250, 2016

12. Chen DY, Wei HJ, Lin KJ, Huang CC, Wang CC, Wu CT, Chao KT, Chen KJ, Chang Y, Sung HW: Three-dimensional cell aggregates composed of HUVECs and cbMSCs for therapeutic neovascularization in a mouse model of hindlimb ischemia. Biomaterials 34:1995-2004, 2013

13. Chen S, Chen X, Wu X, Wei S, Han W, Lin J, Kang M, Chen L: Hepatocyte growth factor-modified mesenchymal stem cells improve ischemia/reperfusion-induced acute lung injury in rats. Gene Ther 24(1):3-11, 2017

14. Chopp M, Li Y: Treatment of neural injury with marrow stromal cells. Lancet Neurology 1:92-100, 2002

15. d'Avila JC, Lam TI, Bingham D, Shi J, Won SJ, Kauppinen TM, Massa S, Liu J, Swanson RA: Microglial activation induced by brain trauma is suppressed by post-injury treatment with a PARP inhibitor. J Neuroinflammation 9: 31, 2012 
16. Di Nicola M, Carlo-Stella C, Magni M, Milanesi M, Longoni PD, Matteucci P, Grisanti S, Gianni AM: Human bone marrow stromal cells suppress T-lymphocyte proliferation induced by cellular or nonspecific mitogenic stimuli. Blood 99:3838-3843, 2002

17. Dong HJ, Shang CZ, Li G, Niu Q, Luo YC, Yang Y, Meng HP, Yin HJ, Zhang HX, Zhao ML, Lin L: The Distribution of transplanted umbilical cord mesenchymal stem cells in large blood vessel of rats with traumatic brain injury. J Craniofac Surg 28:1615-1619,2017

18. Hasan A, Deeb G, Rahal R, Atwi K, Mondello S, Marei HE, Gali A, Sleiman E: Mesenchymal stem cells in the treatment of traumatic brain injury. Front Neurol 8: 28, 2017

19. Hayashi T, Deguchi K, Nagotani S, Zhang H, Sehara Y, Tsuchiya A, Abe K: Cerebral ischemia and angiogenesis. Curr Neurovasc Res 3: 119-129, 2006

20. Helmy A, De Simoni MG, Guilfoyle MR, Carpenter KL, Hutchinson PJ: Cytokines and innate inflammation in the pathogenesis of human traumatic brain injury. Prog Neurobiol 95: 352-372, 2011

21. Hofer HR, Tuan RS: Secreted trophic factors of mesenchymal stem cells support neurovascular and musculoskeletal therapies. Stem Cell Res Ther 7:131, 2016

22. Huajiang D, Chongzhi S, Gang L, Yuechen L, Yue Y, Ling L, Mingliang Z: Differential protein expression in an acute disseminated myelitis patient after treatment with umbilical cord mesenchymal stem cells. Int J Clin Exp Med 10:72137219, 2017

23. Huang C, Zhao L, Gu J, Nie D, Chen Y, Zuo H, Huan W, Shi J, Chen J, Shi W: The migration and differentiation of hUC-MSCs (CXCR4/GFP) encapsulated in BDNF/chitosan scaffolds for brain tissue engineering. Biomed Mater 11: 035004, 2016

24. Huang CC, Chen DY, Wei HJ, Lin KJ, Wu CT, Lee TY, Hu HY, Hwang SM, Chang Y, Sung HW: Hypoxia-induced therapeutic neovascularization in a mouse model of an ischemic limb using cell aggregates composed of HUVECs and cbMSCs. Biomaterials 34: 9441-9450, 2013

25. Joyce N, Annett G, Wirthlin L, Olson S, Bauer G, Nolta JA: Mesenchymal stem cells for the treatment of neurodegenerative disease. Regen Med 5: 933-946, 2010

26. Kassis I, Vaknin-Dembinsky A, Karussis D: Bone marrow mesenchymal stem cells: Agents of immunomodulation and neuroprotection. Curr Stem Cell Res Ther 6: 63-68, 2011

27. Kopen GC, Prockop DJ, Phinney DG: Marrow stromal cells migrate throughout forebrain and cerebellum, and they differentiate into astrocytes after injection into neonatal mouse brains. Proc Natl Acad Sci U S A 96: 10711-10716, 1999

28. Kurozumi K, Nakamura K, Tamiya T, Kawano Y, Ishii K, Kobune M, Hirai S, Uchida H, Sasaki K, Ito Y, Kato K, Honmou $\mathrm{O}$, Houkin K, Date I, Hamada H: Mesenchymal stem cells that produce neurotrophic factors reduce ischemic damage in the rat middle cerebral artery occlusion model. Mol Ther 11: 96104, 2005

29. Kwon YW, Heo SC, Jeong GO, Yoon JW, Mo WM, Lee MJ, Jang $\mathrm{IH}$, Kwon SM, Lee JS, Kim JH: Tumor necrosis factor-alpha-activated mesenchymal stem cells promote endothelial progenitor cell homing and angiogenesis. Biochim Biophys Acta 1832: 2136-2144, 2013
30. Le Blanc K, Tammik C, Rosendahl K, Zetterberg E, Ringden O: HLA expression and immunologic properties of differentiated and undifferentiated mesenchymal stem cells. Exp Hematol 31: 890-896, 2003

31. Lee JK, Jin HK, Endo S, Schuchman EH, Carter JE, Bae JS: Intracerebral transplantation of bone marrow-derived mesenchymal stem cells reduces amyloid-beta deposition and rescues memory deficits in Alzheimer's disease mice by modulation of immune responses. Stem Cells 28:329-343, 2010

32. Lee ST, Chu K, Jung KH, Kim SJ, Kim DH, Kang KM, Hong NH, Kim JH, Ban JJ, Park HK, Kim SU, Park CG, Lee SK, Kim M, Roh JK: Anti-inflammatory mechanism of intravascular neural stem cell transplantation in haemorrhagic stroke. Brain 131: 616-629, 2008

33. Leker RR, Shohami E: Cerebral ischemia and traumadifferent etiologies yet similar mechanisms: Neuroprotective opportunities. Brain Res Brain Res Rev 39:55-73, 2002

34. Lu LL, Liu YJ, Yang SG, Zhao QJ, Wang X, Gong W, Han ZB, Xu ZS, Lu YX, Liu D, Chen ZZ, Han ZC: Isolation and characterization of human umbilical cord mesenchymal stem cells with hematopoiesis-supportive function and other potentials. Haematologica 91:1017-1026, 2006

35. Lucas SM, Rothwell NJ, Gibson RM: The role of inflammation in CNS injury and disease. Br J Pharmacol 147 Suppl 1: S232240, 2006

36. Luo C, Zhu C: Molecular biology study of traumatic brain injury. Chin J Traumatol 16: 62-64, 2000

37. Luo C, Zhu C, Jiang J, Lu Y, Zhang G, Yuan G, Cai R, Ye $\mathrm{T}$ : Alterations of bcl-2, bcl-x and bax protein expressions in area CA-3 of rat hippocampus following fluid percussion brain injury. Chin J Traumatol 2:101-104, 1999

38. Maas Al, Stocchetti N, Bullock R: Moderate and severe traumatic brain injury in adults. Lancet Neurol 7: 728-741, 2008

39. Maitra B, Szekely E, Gjini K, Laughlin MJ, Dennis J, Haynesworth SE, Koc ON: Human mesenchymal stem cells support unrelated donor hematopoietic stem cells and suppress T-cell activation. Bone Marrow Transplant 33:597604, 2004

40. Marshall LF: Head injury: Recent past, present, and future. Neurosurgery 47:546-561, 2000

41. Mclntosh TK: Neurochemical sequelae of traumatic brain injury: Therapeutic implications. Cerebrovasc Brain Metab Rev 6:109-162, 1994

42. Meirelles Lda S, Fontes AM, Covas DT, Caplan Al: Mechanisms involved in the therapeutic properties of mesenchymal stem cells. Cytokine Growth Factor Rev 20:419-427, 2009

43. Menge T, Zhao Y, Zhao J, Wataha K, Gerber M, Zhang J, Letourneau P, Redell J, Shen L, Wang J, Peng Z, Xue H, Kozar R, Cox CS Jr, Khakoo AY, Holcomb JB, Dash PK, Pati S: Mesenchymal stem cells regulate blood-brain barrier integrity through TIMP3 release after traumatic brain injury. Sci Transl Med 4: 161ra150, 2012

44. Mezey E, Chandross KJ, Harta G, Maki RA, McKercher SR: Turning blood into brain: Cells bearing neuronal antigens generated in vivo from bone marrow. Science 290:1779-1782, 2000 
45. Moodley Y, Sturm M, Shaw K, Shimbori C, Tan DB, Kolb M, Graham R: Human mesenchymal stem cells attenuate early damage in a ventilated pig model of acute lung injury. Stem Cell Res 17: 25-31, 2016

46. Morganti-Kossmann MC, Satgunaseelan L, Bye N, Kossmann T: Modulation of immune response by head injury. Injury 38 : 1392-1400, 2007

47. Nemeth K, Leelahavanichkul A, Yuen PS, Mayer B, Parmelee A, Doi K, Robey PG, Leelahavanichkul K, Koller BH, Brown JM, Hu X, Jelinek I, Star RA, Mezey E: Bone marrow stromal cells attenuate sepsis via prostaglandin $E(2)$-dependent reprogramming of host macrophages to increase their interleukin-10 production. Nat Med 15:42-49, 2009

48. Neuhuber B, Timothy Himes B, Shumsky JS, Gallo G, Fischer I: Axon growth and recovery of function supported by human bone marrow stromal cells in the injured spinal cord exhibit donor variations. Brain Res 1035: 73-85, 2005

49. Ooi YY, Ramasamy R, Rahmat Z, Subramaiam H, Tan SW, Abdullah $\mathrm{M}$, Israf DA, Vidyadaran S: Bone marrow-derived mesenchymal stem cells modulate BV2 microglia responses to lipopolysaccharide. Int Immunopharmacol 10:1532-1540, 2010

50. Pandya NM, Dhalla NS, Santani DD: Angiogenesis-a new target for future therapy. Vascul Pharmacol 44: 265-274, 2006

51. Park E, Bell JD, Baker AJ: Traumatic brain injury: Can the consequences be stopped? CMAJ 178:1163-1170, 2008

52. Parr AM, Tator $\mathrm{CH}$, Keating A: Bone marrow-derived mesenchymal stromal cells for the repair of central nervous system injury. Bone Marrow Transplant 40:609-619, 2007

53. Raghupathi R, Conti AC, Graham DI, Krajewski S, Reed JC, Grady MS, Trojanowski JQ, Mclntosh TK: Mild traumatic brain injury induces apoptotic cell death in the cortex that is preceded by decreases in cellular Bcl-2 immunoreactivity. Neuroscience 110: 605-616, 2002

54. Rao MS, Mattson MP: Stem cells and aging: Expanding the possibilities. Mech Ageing Dev 122: 713-734, 2001

55. Rhodes J: Peripheral immune cells in the pathology of traumatic brain injury? Curr Opin Crit Care 17:122-130, 2011

56. Rota C, Morigi M: Use of mesenchymal stem cells of different origins in the treatment of acute renal failure. G Ital Nefrol 28: 573-575, 2011 (In Italian)

57. Sabel BA, Dunbar GL, Stein DG: Gangliosides minimize behavioral deficits and enhance structural repair after brain injury. J Neurosci Res 12:429-443, 1984

58. Scuteri A, Miloso M, Foudah D, Orciani M, Cavaletti G, Tredici G: Mesenchymal stem cells neuronal differentiation ability: $A$ real perspective for nervous system repair? Curr Stem Cell Res Ther 6: 82-92, 2011

59. Sheikh AM, Nagai A, Wakabayashi K, Narantuya D, Kobayashi S, Yamaguchi S, Kim SU: Mesenchymal stem cell transplantation modulates neuroinflammation in focal cerebral ischemia: Contribution of fractalkine and IL-5. Neurobiol Dis 41: 717-724, 2011
60. Shen WC, Liang CJ, Wu VC, Wang SH, Young GH, Lai IR, Chien CL, Wang SM, Wu KD, Chen YL: Endothelial progenitor cells derived from Wharton's jelly of the umbilical cord reduces ischemia-induced hind limb injury in diabetic mice by inducing HIF-1alpha/IL-8 expression. Stem Cells Dev 22:1408-1418, 2013

61. Si YL, Zhao YL, Hao HJ, Fu XB, Han WD: MSCs: Biological characteristics, clinical applications and their outstanding concerns. Ageing Res Rev 10:93-103, 2011

62. Tajiri N, Kaneko $Y$, Shinozuka K, Ishikawa $H$, Yankee E, McGrogan M, Case C, Borlongan CV: Stem cell recruitment of newly formed host cells via a successful seduction? Filling the gap between neurogenic niche and injured brain site. PLoS One 8: e74857, 2013

63. Tang J, Xie Q, Pan G, Wang J, Wang M: Mesenchymal stem cells participate in angiogenesis and improve heart function in rat model of myocardial ischemia with reperfusion. Eur $\mathrm{J}$ Cardiothorac Surg 30: 353-361, 2006

64. Tang YL, Zhao Q, Qin X, Shen L, Cheng L, Ge J, Phillips Ml: Paracrine action enhances the effects of autologous mesenchymal stem cell transplantation on vascular regeneration in rat model of myocardial infarction. Ann Thorac Surg 80: 229-237, 2005

65. Tse WT, Pendleton JD, Beyer WM, Egalka MC, Guinan EC: Suppression of allogeneic T-cell proliferation by human marrow stromal cells: Implications in transplantation. Transplantation 75: 389-397, 2003

66. Turrin NP, Rivest S: Tumor necrosis factor alpha but not interleukin 1 beta mediates neuroprotection in response to acute nitric oxide excitotoxicity. J Neurosci 26: 143-151, 2006

67. Uccelli A, Moretta L, Pistoia V: Mesenchymal stem cells in health and disease. Nat Rev Immunol 8: 726-736, 2008

68. Vendrame M, Gemma C, de Mesquita D, Collier L, Bickford PC, Sanberg CD, Sanberg PR, Pennypacker KR, Willing AE: Anti-inflammatory effects of human cord blood cells in a rat model of stroke. Stem Cells Dev 14:595-604, 2005

69. Volarevic V, Arsenijevic N, Lukic ML, Stojkovic M: Concise review: Mesenchymal stem cell treatment of the complications of diabetes mellitus. Stem Cells 29: 5-10, 2011

70. Walker PA, Shah SK, Harting MT, Cox CS Jr: Progenitor cell therapies for traumatic brain injury: Barriers and opportunities in translation. Dis Model Mech 2: 23-38, 2009

71. Wan J, Cai Q, Liu Y: Effect of intramuscular bone marrowderived mesenchymal stem cell transplantation in the leg for treatment of diabetic foot ulcers in rats. Nan Fang Yi Ke Da Xue Xue Bao 32:1730-1736, 2012 (In Chinese)

72. Weiss ML, Mitchell KE, Hix JE, Medicetty S, El-Zarkouny SZ, Grieger D, Troyer DL: Transplantation of porcine umbilical cord matrix cells into the rat brain. Exp Neurol 182:288-299, 2003

73. Whiteley J, Bielecki R, Li M, Chua S, Ward MR, Yamanaka N, Stewart DJ, Casper RF, Rogers IM: An expanded population of CD34+ cells from frozen banked umbilical cord blood demonstrate tissue repair mechanisms of mesenchymal stromal cells and circulating angiogenic cells in an ischemic hind limb model. Stem Cell Rev 10:338-350, 2014 
74. Winter CD, Pringle AK, Clough GF, Church MK: Raised parenchymal interleukin-6 levels correlate with improved outcome after traumatic brain injury. Brain 127:315-320, 2004

75. Wu KH, Zhou B, Yu CT, Cui B, Lu SH, Han ZC, Liu YL: Therapeutic potential of human umbilical cord derived stem cells in a rat myocardial infarction model. Ann Thorac Surg 83: 1491-1498, 2007

76. Xuan W, Vatansever F, Huang L, Wu Q, Xuan Y, Dai T, Ando T, Xu T, Huang YY, Hamblin MR: Transcranial low-level laser therapy improves neurological performance in traumatic brain injury in mice: Effect of treatment repetition regimen. PLoS One 8: e53454, 2013

77. Yuan Y, Yang SY, Han ZC, Zhang XH: Isolation, purification and biological characteristics of human umbilical cord mesenchymal stem cells. Chin J Exp Surg 23:118, 2006

78. Yuan Y, Yang SY, Zhang JN: Human umbilical cord derived mesenchymal stem cell transplantation for rat traumatic brain injury. Journal of Clinical Rehabilitative Tissue Engineering Research 15: 8424-8428, 2010

79. Zachary I: Signaling mechanisms mediating vascular protective actions of vascular endothelial growth factor. Am J Physiol Cell Physiol 280: C1375-1386, 2001

80. Zadeh G, Guha A: Angiogenesis in nervous system disorders. Neurosurgery 53: 1362-1374; discussion 1374-1376, 2003
81. Zhang B, Wu X, Zhang X, Sun Y, Yan Y, Shi H, Zhu Y, Wu L, Pan Z, Zhu W, Qian H, Xu W: Human umbilical cord mesenchymal stem cell exosomes enhance angiogenesis through the Wnt4/ beta-catenin pathway. Stem Cells Transl Med 4:513-522, 2015

82. Zhang $H$, Xiang $M$, Meng $D$, Sun $N$, Chen S: Inhibition of myocardial ischemia/reperfusion injury by exosomes secreted from mesenchymal stem cells. Stem Cells Int 2016:4328362, 2016

83. Zhang R, Liu Y, Yan K, Chen L, Chen XR, Li P, Chen FF, Jiang $X D$ : Anti-inflammatory and immunomodulatory mechanisms of mesenchymal stem cell transplantation in experimental traumatic brain injury. J Neuroinflammation 10:106, 2013

84. Zhao Y, Gibb SL, Zhao J, Moore AN, Hylin MJ, Menge T, Xue $H$, Baimukanova G, Potter D, Johnson EM, Holcomb JB, Cox CS Jr, Dash PK, Pati S: Wnt3a, a protein secreted by mesenchymal stem cells is neuroprotective and promotes neurocognitive recovery following traumatic brain injury. Stem Cells 34:1263-1272, 2016

85. Ziebell JM, Morganti-Kossmann MC: Involvement of proand anti-inflammatory cytokines and chemokines in the pathophysiology of traumatic brain injury. Neurotherapeutics 7: 22-30, 2010 